\title{
ANÁLISE DO ETHOS DISCURSIVO CEARENSE DE MULHERES PROJETADO A PARTIR DA CAMPANHA "O QUE ELAS TÊM A DIZER"
}

\section{ANALYSIS OF THE ETHOS DISCURSIVE CEARENSE OF WOMEN DESIGNED FROM THE CAMPAIGN "WHAT THEY HAVE TO SAY"}

\author{
Rakel Beserra de Macêdo Viana ${ }^{1}$ \\ Iara de Sousa Nascimento ${ }^{2}$ \\ Naara Lima Ripardo ${ }^{3}$ \\ Ludovica Olímpio Magalhães ${ }^{4}$
}

Resumo: Analisamos a imagem discursiva (ethos) cearense de mulheres projetada em uma campanha chamada $O$ que elas têm a dizer, em comemoração ao Dia Internacional da Mulher. Para tal, utilizamos a noção de ethos da Análise do Discurso Crítica (ADC), postulada por Fairclough (2001 [1992]), e as noções de feminilidade e feminilitude de Martins Ferreira (2002), além da problematização trazida por Saffioti (1987) acerca da relação gênero-raçaclasse. Os dados foram analisados localizando o discurso direto e a investigação da construção dos ethes através dos mecanismos de intertextualidade e ocorrências verbais. Verificou-se que, por mais que exista um ethos de fragilidade, percebeu-se um ethos de empoderamento e pertença de coletivo em seus discursos.

Palavras-chave: ethos feminino, análise do discurso crítica, mulher.

Abstract: We analyzed the discursive image (ethos) about the female from Ceará projected in a campaign called What do they have to say, in celebration of International Women's Day. For this, we used the notion of ethos from Critical Discourse Analysis (ADC), postulated by Fairclough (2001 [1992]), and Martins Ferreira's (2002) notions of femininity and femininity, besides the problematization brought by Saffioti (1987) about the gender-race-class relationship. The data were analyzed by locating the direct speech and the investigation of the construction of the ethes through the intertextuality mechanisms and verbal occurrences. It was found that, although there is an ethos of fragility, an ethos of empowerment and collective belonging was perceived in her speeches.

Keywords: feminine ethos, critical discourse analysis, woman.

\section{Introdução}

\footnotetext{
1 Doutoranda e mestre pelo Programa de Linguística Aplicada da Universidade Estadual do Ceará PosLA/UECE, professora da rede estadual de Ensino Básico, e-mail: rakelbeserra@ gmail.com

2 Mestranda do Programa de Linguística Aplicada da Universidade Estadual do Ceará - PosLA/UECE, e-mail: yara.sousa@aluno.uece.br

3 Mestranda do Programa de Linguística Aplicada da Universidade Estadual do Ceará - PosLA/UECE, e-mail: naaralimaripardo@yahoo.com.br

4 Mestranda do Programa de Linguística Aplicada da Universidade Estadual do Ceará - PosLA/UECE, professora do Instituto Federal do Ceará - IFCE - Campus Tauá-CE, e-mail: ludovica.magalhaes@ifce.edu.br
} 
Desde o século XIX, com o ingresso das mulheres no cenário político através da Declaração dos Direitos do Homem e do Cidadão e, posteriormente, com a inauguração do Movimento Sufragista em 1848 (GARCIA, 2011), a vida de mulheres quase que pelo mundo inteiro vem se modificando, mesmo que à passos curtos e lentos.

No atual cenário brasileiro, existem práticas sociais que, fortalecidas por seus respectivos discursos, culminam em abusos de poder, agressões físicas e morais, desigualdade salarial e, em última instância, feminicídios, a exemplo da prática social já naturalizada de responsabilizar a mulher pelo cuidado do lar e pela maternidade, colocando-a em uma posição onde dificilmente haverá espaço para a ascensão salarial, tornando-a sujeita à abusos domésticos e a uma sobrecarga de funções. De outro, existem as práticas que resultam no crescimento e maior alcance do movimento feminista, fenômeno que se dá, em grande parte, pela massificação das redes sociais e difusão de informações. Esta aparente dualidade não deve ser compreendida como uma simples ambivalência contraditória, pois práticas sociais estão a serviço de forças ideológicas maiores, sendo exercidas por diferentes grupos sociais e não recebem o mesmo peso e medida, visto que as últimas buscam operar uma força contrahegemônica em relação às primeiras.

Como resultado dessa espécie de "popularização" do feminismo, temos, por exemplo, um investimento de mídias, como jornais, em dedicar um espaço maior às pautas femininas, expondo problemas e desigualdades que circundam o dia a dia das mulheres. Obviamente, sabese que essa mudança se dá, em segundo plano, devido a interesses capitalistas que visam somente o lucro. Ainda assim, essa nova configuração também nos revela uma mudança de interesse do público que consome tais materiais.

Em março de 2019 o Sistema TV Verdes Mares, através do Jornal Diário do Nordeste, lançou um projeto intitulado "O que elas têm a dizer", uma homenagem no mês de março - em virtude da data do Dia Internacional da Mulher -, dedicado às mulheres como uma maneira de dar espaço à voz feminina cearense. A partir disso, enxergamos em tal projeto um profícuo corpus para verificarmos quais figuras femininas surgem no cenário jornalístico cearense. Vejamos qual a proposta do projeto, nas palavras da redação do jornal:

Todos os dias mulheres são silenciadas em suas casas, em seus trabalhos, nas universidades e também nos espaços públicos. São opiniões, decisões, argumentos e pedidos de socorro negligenciados. Pensando em dar voz para as histórias, angústias, conquistas e denúncias de várias mulheres, o Sistema Verdes Mares criou a campanha "O que as mulheres têm a dizer", que envolverá todos nossos veículos. Conte para nós a sua história, a luta e exemplo de superação de uma outra mulher ou denuncie abusos 
e crimes contra as nossas mulheres. Multiplique essa campanha e interaja conosco ainda nas redes sociais através da hashtag \#oqueasmulheretemadizer. (Diário do Nordeste, março de 2019. Disponível em: https://diariodonordeste.verdesmares.com.br/editorias/metro/sistema-verdes-mareslanca-campanha-sobre-empoderamento-feminino-1.2069685).

Com a divulgação do projeto nos telejornais e na internet, o jornal passou a receber via redes sociais e internet, com o uso da hashtag \#oqueasmulheretemadizer, diversos relatos de mulheres sobre suas vidas, assim como reportagens sobre grandes nomes femininos da história cearense. Já no mesmo mês, a rede lançou matérias e reportagens escritas por seus jornalistas sobre figuras femininas cearenses.

Diante de tal iniciativa, objetivamos com esta pesquisa, analisar quais ethé discursivos emergem de tal material. Nosso corpus se constituirá das reportagens que apresentam relatos dos sujeitos femininos atuais, e nossa ferramenta teórico-metodológica será a Análise de Discurso Crítica (ADC) segundo a abordagem dialético-relacional de Norman Fairclough (2001 [1992]), referencial do qual também extraímos a conceituação de ethos, além das noções de feminilidade e feminilitude problematizadas por Martins Ferreira (2002).

Ademais, julgamos importante também que, diante do nosso cenário sócio-histórico, ressaltar o fato de que os Estudos Críticos, arcabouço maior nos quais nos apoiamos, encontram-se em alto patamar de valia ao nos oferecerem um excelente eixo teóricometodológico para realizarmos pesquisas de cunho investigativo e ético.

Assim, a escolha pela ADC de orientação dialético-relacional como embasamento para o desenvolvimento desta pesquisa justifica-se por ela oferecer a possibilidade de empreender uma pesquisa que visa o desvelamento dos mecanismos de poder que regem as relações de dominação, mais especificamente, nos auxiliando na compreensão de como o poder exercido pela hegemonia machista ainda atua, ou não, sob a vida das mulheres cearenses na construção de suas identidades.

Este artigo está dividido em seis seções. Após a introdução, apresentamos as/ao leitora/or três seções teóricas, a saber: a Análise de Discurso Crítica, Ethos, Feminilidade e Feminilitude e a tríade gênero-raça-classe, no qual trazemos o percurso teórico que trilhamos para análise do corpus. Seguindo o texto, trazemos o caminho metodológico adotado por nós, assim como, a análise dos dados, dividida em duas subseções: processos verbais e intertextualidade, para uma análise mais detalhada dos dados. Por fim, nossas considerações finais que encerram o estudo proposto e as referências que foram base de todo o texto. 


\section{A Análise de Discurso Crítica}

A ADC, que firmou-se como disciplina em meados da década de 90, em um simpósio que aconteceu em Amsterdã, tem como influências a Linguística Crítica e a Linguística Sistêmico-Funcional e possui várias abordagens, dentre elas: a abordagem histórico-discursiva, de Reisigl e Wodak; a da linguística de corpus, de Mautner; a abordagem de atores sociais, tendo como expoente Van Leeuwen; a Análise de dispositivo, em Jäger e Maier; a Sociocognitiva, em Van Dijk; e a Dialético-Relacional, em Norman Fairclough. Sendo uma disciplina de caráter transdisciplinar e interdisciplinar, busca diálogo com outras disciplinas, a fim de diversificar e aprofundar o estudo do papel da linguagem nas práticas sociais. Logo, o foco é compreender como propriedades de micronível da linguagem estão relacionadas com as de macronível, analisando, também, os efeitos ideológicos causados nos atores sociais com fins de dominação e/ou exploração.

Situada nos Estudos Críticos, a ADC não só estuda os problemas sociais, mas também se posiciona politicamente, permitindo um envolvimento do pesquisador com o objeto analisado e uma desestruturação das consciências cristalizadas pelas relações assimétricas de poder.

Para o objetivo deste artigo, no caso, a análise do ethos de mulheres a partir de uma campanha jornalística cearense, usaremos a abordagem dialético-relacional de Norman Fairclough (2001 [1992]). Tal abordagem compreende o texto como unidade mínima de análise, e nele são materializados os discursos dos eventos que emergem a partir das práticas sociais. Dentre eles, podemos citar a fala, a escrita e a imagem (Magalhães, 2017). O discurso refere-se a todas as formas de texto, sejam elas escritas ou faladas, pertencentes a um determinado grupo social, em um momento particular na história, ou seja, uma forma de prática social, um elemento que juntamente com outros, constitui essa prática.

O termo "discurso" tem um duplo sentido: significa discursos de forma abstrata, referente ao conceito, e também, discursos particulares, concretos, representando visões de mundo, por exemplo, os discursos políticos e feministas. Já o poder diz respeito ao controle exercido por algum grupo da sociedade sobre os demais sujeitos presentes nesse contexto situacional. É relativamente estável, pois, devido à relação dialética entre linguagem e prática social, é possível que mudanças ocorram, algo que é muito importante para essa abordagem. E ligado ao conceito de poder, temos a hegemonia, que seria o próprio poder em ação, mas de forma velada. 
Quanto a ideologia, como aponta Fairclough:

são significações/construções da realidade (o mundo físico, as relações sociais, as identidades sociais) que são construídas em várias dimensões das formas/sentidos das práticas discursivas e que contribuem para a produção, a reprodução ou a transformação das relações de dominação (FAIRCLOUGH, 2001 [1992], p. 117).

Segundo Resende e Ramalho (2006) há uma mudança no foco da ADC faircloughiana, onde o discurso passa a ser visto como um momento da prática social:

Observa-se que houve, entre os modelos, um movimento do discurso para a prática social, ou seja, a centralidade do discurso como foco dominante da análise passou a ser questionada, e o discurso passou a ser visto como um momento das práticas sociais. (RAMALHO \& RESENDE, 2006, p. 29. grifo das autoras).

Tal mudança de foco foi de grande relevância, pois, considerar o discurso como um momento da prática social e não na centralidade da análise, significa a existência de outros momentos desta prática e que o discurso constitui-se e é constituído nesta relação, abrindo espaço também, para que nos debrucemos sob uma pesquisa que investigue as relações de poder de modo mais abrangente, sem reduzir nem ampliar em desmedida o papel do discurso. Tais conceitos são essenciais para que se possa compreender tal abordagem em ADC. E a partir dela, veremos na próxima seção deste artigo, o que é o ethos e como ele se manifestaria no texto.

\section{Ethos}

A discussão sobre ethos varia de área para área. Assim, Irineu (2014) nos apresenta, em sua tese, um glossário sobre o que seria o ethos a partir da visão de diferentes autores. Para Maingueneau (2011), o ethos se constrói no discurso, como um fenômeno interativo, situado sócio-historicamente que pode ser apreendido durante a comunicação. Em Charaudeau (2008), o Ethos também é de natureza dialógica, e está relacionado às imagens de si que os sujeitos (locutores) produzem durante a comunicação. Segundo Discini (2011), essa categoria é de caráter dialógico e responsivo, expressando as formações sociais que constroem as imagens dos enunciadores. Gonçalves (2006) também parte do pressuposto que o Ethos é dialógico e diz respeito tanto ao enunciador quanto ao coenunciador, e tem sua realização na cadeia discursiva, em diferentes gêneros e discursos. Pode ser materializado em textos orais ou escritos, estendendo-se para diferentes sistemas semióticos. 
Já, para Fairclough (2001 [1992]), o ethos é um fenômeno intertextual amplo, que visa a construção da identidade social dos sujeitos, e também contribui para que mudanças culturais ocorram. É considerado não só as diferentes vozes que compõem um determinado discurso, e a remodelagem de tais vozes de acordo com a preferência do falante, mas também, a postura desse, e a organização do ambiente em que ele fala.

Em conformidade com o que aqui pretendemos apresentar, consideramos a importância do discurso para a constituição das estruturas sociais (FAIRCLOUGH, 2001 [1992]). Desta forma, o discurso funciona como mantenedor das relações ideológicas, ao passo que reproduz crenças, estereótipos e juízos de valores, contudo, enquanto prática social e não apenas como uma representação do mundo, o discurso também pode se realizar de maneira a romper posições de poder já naturalizadas, resistindo às interpelações ideológicas.

Ademais, como noções a serem problematizadas a partir de nossos resultados, e de maneira a oferecer uma análise mais reflexiva, abordaremos os conceitos de feminilidade e feminilitude aportadas em Martins Ferreira (2002), bem como a concepção de gênero-raçaclasse sugeridas por Saffioti (1987), a seguir.

\section{Feminilidade e Feminilitude}

Como fio norteador para a compreensão dos termos feminilidade e feminilitude, nos apropriamos dos conceitos utilizados por Martins Ferreira (2002) que traz a ideia de que a Feminilidade se trata de uma construção de padrões culturais de comportamento. Esses comportamentos são baseados em arquétipos patriarcais, que enquadram as mulheres em categorias das quais se é atribuído grande valor. Essas categorias são divididas em beleza, sensibilidade, meiguice, submissão, maternidade.

A ideia de Feminilitude, também tem sua raiz em um conceito cultural, atual, onde mostra a mulher como uma figura forte, que tem seu papel e sua participação ativa e extremamente produtiva na sociedade. Essa figura adquire vários papéis dentro dessa sociedade, como, por exemplo, a de mãe e educadora. Segundo essa ideia, a mulher é vista como um ser amplamente criativo e independente. Essa noção também traz em contrapartida uma crítica a correntes anteriores que valorizam o ser masculino como representante do ser humano, universal, racional.

As correntes Queer e Feminilitude baseiam-se em críticas às correntes Marxistas ou Do Patriarcado, às noções de sujeito universal, racional, masculino, como representante do 
humano; são reconhecidas como teorias feministas pós-estruturalistas por tomarem como base para suas reflexões, autores representantes da escola filosófica de mesmo nome $-\mathrm{M}$. Foucault, J. Derrida, e outros. Tais correntes recorrem a essas teorizações, de modo a desconstruir dicotomias que presidem o modo de pensar da mulher. (GALINKIN; ISMAEL, 2011, p. 534).

A teoria Queer foi primeiramente idealizada por escritores e ativistas, tendo seu início nas ciências humanas com estudos nas áreas de Literatura e Linguística, especificamente no Discurso. Essa teoria é resultado de estudos sobre a discriminação da mulher, o tratamento a ela dispensado, bem como, questões relacionadas a sua sexualidade. Em uma perspectiva Foucaultiana, a teoria Queer pode ser vista como o estudo de relações de poder.

Podemos perceber que existem, pelo menos aparentemente, entre esses dois conceitos atribuídos às mulheres marcas de antagonismo. Onde a feminilidade revela padrões patriarcais, ultrapassados, que sugerem fragilidade. Dessa forma, reproduzindo um arquétipo que sugira que a mulher seja vista muitas vezes como mais fraca e incapaz. Já a feminilitude, revela padrões modernos, onde a mulher é protagonista de sua própria história. Essa mulher, por si só, controla suas decisões, suas atitudes, seu tempo e gerencia todas as coisas ao seu redor, abrindo mão, muitas vezes, de seus traços supostamente naturais de doçura e sensibilidade, devido a situações a quem são expostas, tendo que muitas vezes superar seus medos, rejeições e até mesmo violências físicas e psicológicas.

Contudo, é importante salientar que as noções de Feminilidade e Feminilitude não devem ser interpretadas de modo polarizado e absolutamente estável. É necessário afirmarmos que tais acepções partem de configurações mais ou menos estabilizadas de como o ser mulher manifesta sua identidade, sendo improvável que uma mulher seja inteiramente caracterizada com uma ou outra noção, havendo comumente uma mescla que irá variar conforme o contexto em que está inserida e sua formação ideológica, marcando sua fluidez.

Por último, mas não menos importante, quando tratamos de identidades femininas, é também essencial que voltemos, ainda que minimamente, nosso olhar para as questões em torno da discussão da relação entre gênero, raça e classe. Saffioti (1987) esclarece que dentro do processo de construção social da inferioridade feminina, há a manutenção e disseminação de preconceitos que são protagonizados, sobretudo, por aqueles a quem interessam mais as relações de dominação e exploração econômica (e sexual), fazendo com que o preconceito vire a norma e seja reproduzido naturalmente por todas as classes sociais. De modo análogo, o mesmo acontece com a população negra, que desde a edificação de nosso país vem sendo explorada e marginalizada pela hegemonia branca e rica. 
A tríade gênero-raça-classe, mesmo que de modo separado, é responsável em grande parte, se não inteiramente, pelo sistema de dominação masculina. Saffioti nos esclarece que:

[...] o patriarcado-racismo-capitalismo beneficia, em primeiro lugar, o homem rico, branco e adulto. Em segundo plano, na ordem dos beneficiados, vem a mulher rica, branca e adulta. Esta segunda posição e bastante diversa da primeira, uma vez que envolve a dependência da mulher em relação ao homem. De qualquer forma, a mulher burguesa sofre em situação de maior conforto que a mulher pobre. (SAFFIOTI, 1987, p. 67)

Assim, incluir nas bases de nossa lente investigativa a consciência da implícita relação do trio acima, nos faz enxergar que, ao desempenharmos críticas sobre as práticas discursivas que o consolida, estamos, simultaneamente, contribuindo para a desestabilização de todo este conjunto, assim como afirma Saffioti: "estes três sistemas de dominação-exploração fundiramse de tal maneira, que será impossível transformar um deles, deixando intactos os demais. Disto decorre o fato de que todas as atitudes machistas reforçam a fusão do trio da dominaçãoexploração." (1987, p. 67). Isto é, ao lutarmos contra o machismo, também movemos as estruturas que sustentam as relações desiguais de classe e raça.

Assim, na próxima seção apresentaremos o nosso percurso metodológico para a apreensão dos resultados da pesquisa.

\section{Procedimentos Metodológicos}

Como já apresentado nas seções anteriores, analisaremos os relatos diretos das mulheres em cinco reportagens de uma campanha do Jornal Diário do Nordeste em comemoração ao mês de março, mês que se comemora o dia internacional da mulher.

$\mathrm{Na}$ introdução deste artigo, pudemos observar no projeto do referido jornal, algumas figuras femininas cearenses em destaque. Observamos, ainda, que além de trazer cearenses historicamente conhecidas como Jovita Feitosa - que, mesmo sendo mulher, serviu ao exército na Guerra do Paraguai - o projeto trouxe mulheres comuns: mulheres que venceram além do preconceito, por fugirem do lugar comum feminino, venceram também a violência, a ausência de políticas públicas para a ecologia e para a maternidade em adoção, o vitimismo e a fragilidade.

Decidimos, pois, analisar o discurso direto de cinco dessas mulheres, para verificarmos os ethé contidos em seus diálogos e suas falas nas reportagens. Para essa análise, baseamo-nos na noção de ethos problematizada na ADC por Fairclough (2001), a relação entre gênero, raça 
e classe proposta por Saffioti (1987), e, ainda, as noções de feminilidade e feminilitude trazidas por Martins Ferreira (2002).

Usaremos como categorias de análise a intertextualidade, componente fundamental da noção de ethos aqui utilizada, e os processos verbais, a fim de analisar as marcações acionais dos atores sociais em questão.

Dessa forma, selecionamos aquelas reportagens de mulheres cearenses atuais, como podemos ver suas manchetes a partir do Quadro 1.

Quadro 1 - Reportagens pertencentes ao corpus da pesquisa

\begin{tabular}{|c|l|}
\hline \multicolumn{1}{|c|}{ Reportagem } & \multicolumn{1}{c|}{ Autoria da reportagem } \\
\hline Vítimas de agressões físicas e psicológicas relatam superação & Emanoela Campelo de Melo \\
\hline Mulheres cuidam da natureza através da arte e do voluntariado & Edição \\
\hline $\begin{array}{c}\text { Mãe por adoção conta história de pioneirismo na conquista de licença- } \\
\text { maternidade }\end{array}$ & Kilvia Muniz \\
\hline Pela educação, mulheres vencem desafios e alcançam sonhos & Kilvia Muniz \\
\hline $\begin{array}{c}\text { O encontrar-se é fonte de empoderamento para mulheres do bairro Parque } \\
\text { São Vicente }\end{array}$ & Diego Barbosa \\
\hline
\end{tabular}

Fonte: Elaborado pelas autoras, Fortaleza, 2020.

A análise deu-se nos seguintes passos: (i) leitura completa das reportagens e retirada das falas das mulheres - discurso direto; (ii) análise dos verbos utilizados no discurso das mulheres; (iii) análise da intertextualidade contida nas falas das mulheres; e (iv) análise dos traços de feminilidade e feminilitude contidas no discurso feminino sobre si.

Esses procedimentos foram realizados em duas etapas: primeiramente, em cada reportagem e, em segundo, de forma a verificarmos as recorrências relevantes dos discursos comuns nas cinco reportagens que compõem nosso corpus.

Vejamos a seguir, a análise e discussão dos resultados encontrados.

\section{Análise e discussão dos resultados}

\subsection{Processos verbais}

Nessa análise, partimos do pressuposto de que o discurso e a esfera social estão em uma relação dialética, como nos é apresentado por Fairclough (2001), e de que o ethos é um 
fenômeno intertextual com fins à construção de identidades sociais. A importância de uma análise no nível textual, discursivo e social verifica-se ao levarmos em conta que, assim como postulou o autor, o discurso é um elemento constitutivo do social, e como tal está presente em todas as instâncias da nossa sociedade. Desta forma, entendendo o discurso como prática social, consideramos possível refletir sobre mudanças sociais concretizadas ou em desenvolvimento ao investigarmos sua materialização em práticas discursivas.

Nas reportagens que compuseram o corpus deste trabalho, pudemos notar a presença de algumas marcas textuais e intertextuais que nos permitiram refletir sobre algumas questões pertinentes para o que aqui pretendemos. Vejamos a seguir:

Ao partirmos para a análise dos processos verbais, usados na significação de um processo da realidade (FAIRCLOUGH, 2001 [1992]), ou seja, que tem relação direta com o mundo material e que podem implicar escolhas de cunho ideológico, notamos três manifestações diferentes.

Na primeira, ao falarem de si mesmas, isto é, ao construírem seu ethos, as mulheres optam por verbos na voz passiva: "dói muito em mim", "carrego". Tais processos indicam para nós que, ao falarem de si, as mulheres em questão carregam em suas escolhas sentimentos de passividade, sofrimento, mágoa e inferioridade.

Segundo Saffioti (1987), dentro do processo de construção social da inferioridade feminina, há, em contrapartida, a edificação do domínio masculino: "Mulher dócil é a contrapartida de homem macho. Mulher frágil é a contraparte de macho forte. Mulher emotiva é a outra metade de homem racional. Mulher inferior é a outra face da moeda do macho superior." (SAFFIOTI, 1987, p. 29, grifos da autora). Assim, o fato de as mulheres analogamente as/aos negras/os, tal como os demais grupos sociais marginalizados - se relatarem de modo inferior, justifica-se pela incorporação dessa subordinação de tanto que a ouvem e a sofrem diariamente.

Ainda sobre o posto de fragilidade que é quase exclusivamente ocupado por mulheres (sobretudo as negras), Saffioti (1987) pontua que "à mulher impõe-se a necessidade de inibir toda e qualquer tendência agressiva, pois deve ser dócil, cordata, passiva. Caso ela seja do tipo mulher despachada, deve disfarçar esta qualidade, porquanto esta é uma característica que só é considerada positiva quando presente no homem" (SAFFIOTI, 1987, p. 37, grifos da autora), demonstrando como a mulher-feminilidade é a melhor aceita pela sociedade, visto que o padrão comumente permitido e aprovado é o da opressão feminina. 
Enquanto isso, no segundo caso, verificamos a presença de alguns verbos que denotam características de feminilitude, como exemplo: "denuncio", "digo", "faço", "vou fazer” e "não omito". Esses processos verbais indicam agência ao relatar acontecimentos externos, isto é, marcam a voz ativa ao se reportarem ao mundo exterior, inferindo força, atitude e vontade de dar voz à outras mulheres.

$\mathrm{Na}$ terceira manifestação, identificamos processos verbais no plural, relacionando-se ao sentimento de coletividade, pertencimento a um grupo, como exemplo em: "devemos", "recebemos", "fazemos" e "chegamos". Aqui as mulheres saem de sua situação de sofrimento individual e se agrupam àquelas que partilham do mesmo problema, adquirindo assim, força e representatividade.

Portanto, é possível inferir, através dos processos supracitados, que as atrizes sociais em questão sofreram com a manutenção da ideologia dominante, mas que, em algum momento, resistiram ao interpelamento dessa cultura machista. Assim sendo, identificam-se neste aspecto da análise os ethé de fragilidade, resiliência, empoderamento e coletividade.

\subsection{Intertextualidade}

A escolha da intertextualidade como categoria de análise para nossa pesquisa se justifica pela importância que Fairclough (2001 [1992]) atribui a ela ao discorrer sobre ethos como podemos ver: "A questão do ethos é intertextual: que modelos de outros gêneros e tipos de discurso são empregados para constituir a subjetividade (identidade social, 'eu') dos participantes de interações?” (p. 207). E é em busca desta resposta que seguimos para a análise do ethos via intertextualidade.

Contudo, antes de prosseguirmos, cabe aqui esclarecer os tipos de discursos que encontramos nas matérias jornalísticas das quais retiramos nosso corpus. Em um primeiro plano, identificamos o discurso direto das (os) jornalistas (os) e, em seguida, o discurso indireto, marcado pelo uso de aspas, das mulheres. É neste último tipo que se focou nossa análise, visto que objetivamos analisar diretamente as vozes dos atores sociais em questão.

Dentro do discurso direto das mulheres pudemos notar marcas de outras vozes, ou seja, discursos indiretos, a saber: "presença de elementos atualizados de outro texto em um texto -as citações" (FAIRCLOUGH, 2003, p. 39). Assim, ao se referirem às vozes dos ex-maridos (agressores), as mulheres se reportam a eles como os detentores do poder de manipulação, autoritarismo, ausência de culpa, humilhação e violência física: "Discutiu comigo dizendo que 
eu estava dando atenção a outros homens", "Ficava teimando que nossos filhos eram de outro homem e ficava me esganando mandando eu falar a verdade". Nestes trechos, a referência é feita de maneira indireta a partir do uso da conjunção "que" e a voz masculina é trazida ao discurso ao falar de si mesma, conferindo a si características correspondentes à noção de feminilidade, isto é, o ator social em questão possui um ethos de fragilidade e submissão masculina.

Partindo para o trecho: "[...] da parte dele, tinha que ser 'eu que mando, quem dá as ordens sou eu, você só tem obrigação de fazer'”, identificamos as mesmas características patriarcais descritas no parágrafo anterior, com um tom mais marcadamente autoritário: "quem dá as ordens sou eu", e a submissão é imposta como única escolha: "você só tem obrigação de fazer". Neste exemplo, a referenciação é feita de maneira direta, com o uso de aspas. A respeito disso, Resende e Ramalho (2006, p. 65) nos esclarecem:

\footnotetext{
Para relatar um discurso, pode-se não apenas citar em discurso direto mas também parafrasear, resumir, ecoar em discurso indireto. $\mathrm{O}$ discurso relatado atribui o dito a seu autor, mas a incorporação de elementos de outros textos também pode ser feita sem atribuição explícita como, por exemplo, na paráfrase. Assim, a intertextualidade cobre uma gama diversa de possibilidades.
}

Notamos ainda a referência a um discurso de autoridade que divide espaço com o discurso da feminilidade, instaurando assim uma relação de hierarquia: "Quando adotei a Vitória, uma juíza me disse: nunca uma mãe adotiva teve direito à licença-maternidade. Enem vai ter". Neste caso, o recurso linguístico utilizado para marcar o discurso direto é o uso dos dois pontos. Para além disto, nota-se no discurso da juíza marcas de autoritarismo e negatividade: "e nem vai ter", prática mais comum entre homens.

Como possível explicação para este tipo de enunciação, podemos relembrar que, historicamente, cargos de magistratura são exercidos por homens, onde, comumente, mulheres que alcançam este patamar, tendem a adquirir traços naturalmente mais masculinos para conquistar respeito, assumindo uma postura de sujeito-feminilitude, pois,

apropria-se, [...] sob a ótica do sistema patriarcal de prerrogativas 'masculinas', consideradas atraentes e uteis para seus desempenho social e profissional, cujos sentidos de independência e superioridades conota, o necessário poder viril que necessita para eficácia de sua agência. (MARTINS FERREIRA, 2010, p. 13). 
Portanto, identifica-se aqui, um ethos de submissão e passividade do ator social mulher diante da figura da juíza, que por sua vez, é dotada de feminilitude e revela um ethos de autoritarismo.

Voltando-nos novamente para marcas de feminilidade, temos o trecho: “As vizinhas vinham conversar e olhavam a menina, pálida, dentro de casa. Daí, exortavam logo. 'Railda, cuide dessa menina, não deixe ela sair de casa, não. É doentinha”. Nesta passagem identificamos o discurso direto das vizinhas sinalizado pelo uso das aspas que é direcionado à filha da mulher em questão. A partir dele, identificamos um ethos de passividade e fragilidade na figura da adolescente.

Porém, em um trecho seguinte retratando a fala da garota, notamos um movimento de resistência à tal ethos através do discurso de sua mãe: “"Ela não se intimidou com a doença. Eu acho até que, por conta disso, me incentivava. Eu ficaria condenada a ficar em casa, como antigamente tratavam, né?'. Então, Sângela decidiu. 'Eu não sou doentinha, não posso me entregar a isso. Aí eu me dediquei a estudar. Eu devorava livros por livros.'. O discurso direto aqui é marcado novamente pelas aspas e foi possível identificar, apesar de a mãe da garota possuir um ethos de passividade e conformidade - "eu ficaria condenada a ficar em casa" -um ethos de resistência e superação, mudança social -- "não posso me entregar a isso".

Ademais, ao analisarmos o trecho a seguir, identificamos, na fala da mulher, uma tentativa de reproduzir o tipo de discurso que lhe é comum: "A voz que eu entendo que dizem é pra gente ficar calada, só obedecendo. Não aceitamos mais isso. Se estiver incomodando, a gente grita mesmo, seja em algo que acontece dentro do ônibus ou dentro da nossa própria casa. A questão da igualdade de gênero é quanto ao diálogo que a gente tem que ter com os homens, os companheiros. Porque os filhos percebem as violências e levam, por exemplo, para as suas namoradas, proibindo de usar saia curta. Por que elas não podem usar?”.

Isto é, em: "ficar calada, só obedecendo" e "proibindo usar saia curta", verifica-se um discurso que faz referência à voz machista utilizando-se o recurso das aspas. Contudo, este discurso é trazido à trama para ser combatido e para servir de incentivo à outras mulheres dialogarem sobre questões de gênero - "A questão da igualdade de gênero é quanto ao diálogo que a gente tem que ter com os homens, os companheiros". Nesse sentido, identifica-se o ethos do empoderamento e da mudança social.

Neste sentindo, empreendemos nossa análise em também verificar se nas falas das mulheres haveria alguma referência quanto à relação do machismo com as questões de classe e 
de raça. A priori, em uma leitura completa do corpus, identificamos poucas alusões a algum tipo de trabalho, mesmo que informal exercido por elas. Após o trecho "Dou vida ao que é considerado morto e faço arte com material orgânico", há um comentário da redação do jornal referindo-se a mulher como artesã, assim como em "Ruth tentou o benefício junto à empresa onde trabalhava como professora." e em "fundou em 2017, a AME, Associação de Mulheres Especiais, que atua empoderando mulheres deficientes e cobrando políticas públicas inclusivas", exemplos nos quais é possível inferir que o acesso ao mercado de trabalho, quando possível, oferece às mulheres, além da possibilidade da ascensão de classe, a chance de empoderar-se, assim como nos confirma o seguinte trecho: "Incentivamos mulheres a ler, fazemos intervenções urbanas verificando acessibilidade na cidade. As meninas cegas aprendem a se maquiar, a se vestir direito".

Como já explanado em nosso referencial teórico, é essencial que ampliemos nosso olhar ao dedicarmos atenção para a tríade gênero-raça-classe, pois, assim com afirma Saffioti (1987), tais sistemas estão fundidos de modo que, ao movermos um deles, seja no sentido de fortalecêlos, ou seja, desestabilizá-los, estaremos provocando mudanças nos demais.

Por conseguinte, o machismo, presente tanto na cabeça dos homens quanto na das mulheres, contribui enormemente para a preservação do estado de coisas vigente no Brasil, pleno de injustiças, qualquer que seja o angulo do qual for examinado: das relações homem-mulher, das relações entre as etnias, das relações entre as classes sociais. (SAFFIOTI, 1987, p.67)

Esse estado de coisas é modificado sempre uma mulher ou homem desequilibra a tríade supracitada, isto é, quando uma mulher periférica, por exemplo, alcança a independência financeira, está movendo, mesmo que em diferentes medidas, o composto dominaçãoexploração que atua sobre ela e os demais.

Por fim, elaboramos abaixo um quadro síntese com os ethé identificados e seus respectivos recursos linguísticos:

Quadro 2 - Ethé identificados no corpus da pesquisa

\begin{tabular}{|c|c|c|c|}
\hline ETHÉ IDENTIFICADOS & TRECHO & \multicolumn{2}{|c|}{ RECURSOS LINGUÍSTICOS } \\
\hline Submissão & $\begin{array}{c}\text { "ele chantageava a minha mãe } \\
\text { dizendo que, se fosse } \\
\text { denunciado, ele iria abusar } \\
\text { sexualmente de todas as filhas" }\end{array}$ & $\begin{array}{c}\text { Chantageava } \\
\text { Abusar }\end{array}$ & $\begin{array}{c}\text { Verbos na voz } \\
\text { passiva indicando } \\
\text { a submissão } \\
\text { feminina. }\end{array}$ \\
\cline { 2 - 4 } & $\begin{array}{c}\text { "ele não me deixou dançar com } \\
\text { ninguém" }\end{array}$ & Não me deixou & $\begin{array}{c}\text { Oração na voz } \\
\text { passiva. }\end{array}$ \\
\hline
\end{tabular}




\begin{tabular}{|c|c|c|c|}
\hline & $\begin{array}{l}\text { "Um dia determinou que eu ia } \\
\text { passar a noite em pé" }\end{array}$ & Determinou & \multirow{3}{*}{$\begin{array}{l}\text { Verbos que } \\
\text { indicam } \\
\text { autoridade sobre a } \\
\text { mulher. }\end{array}$} \\
\hline & $\begin{array}{c}\text { "Me batia e depois mandava eu } \\
\text { me olhar no espelho para ver } \\
\text { como tinha ficado" }\end{array}$ & Mandava & \\
\hline & $\begin{array}{c}\text { "Me casei, tive um bom } \\
\text { casamento, mas, da parte dele, } \\
\text { tinha que ser eu que mando, } \\
\text { quem dá as ordens sou eu, você } \\
\text { só tem obrigação de fazer'. E eu } \\
\text { me acostumei, porque vi meu } \\
\text { pai fazendo isso com a minha } \\
\text { mãe." }\end{array}$ & $\begin{array}{c}\text { 'eu mando, quem dá as } \\
\text { ordens sou eu, você só } \\
\text { tem a obrigação de } \\
\text { fazer.' }\end{array}$ & \\
\hline \multirow[t]{5}{*}{ Agência/Empoderamento } & $\begin{array}{l}\text { "Nunca deixe de acreditar em si } \\
\text { mesma. O seu crivo é o mais } \\
\text { importante. Se você } \\
\text { acredita em si e sabe de onde } \\
\text { veio e onde vai chegar, não } \\
\text { importa o caminho." }\end{array}$ & Acreditar & $\begin{array}{l}\text { Verbo na voz } \\
\text { ativa que indica } \\
\text { positividade e } \\
\text { vontade de } \\
\text { empoderar outras } \\
\text { mulheres. }\end{array}$ \\
\hline & $\begin{array}{c}\text { "Dou vida ao que é considerado } \\
\text { morto e faço arte com material } \\
\text { orgânico." }\end{array}$ & $\begin{array}{l}\text { Dou; } \\
\text { Faço. }\end{array}$ & \multirow[t]{4}{*}{$\begin{array}{l}\text { Verbos na voz } \\
\text { ativa indicando } \\
\text { agência e } \\
\text { empoderamento. }\end{array}$} \\
\hline & $\begin{array}{c}\text { "Penso que a primeira coisa que } \\
\text { tem que aparecer é minha arte. } \\
\text { Isso me orgulha } \\
\text { porque é o que sei fazer." }\end{array}$ & $\begin{array}{l}\text { Penso; } \\
\text { Minha; } \\
\text { Orgulha; } \\
\text { Sei. }\end{array}$ & \\
\hline & $\begin{array}{l}\text { "Incentivamos mulheres a ler, } \\
\text { fazemos intervenções urbanas } \\
\text { verificando acessibilidade na } \\
\text { cidade. As meninas chegam } \\
\text { aprendem a se maquiar, a se } \\
\text { vestir direito." }\end{array}$ & $\begin{array}{l}\text { Incentivamos; } \\
\text { Fazemos; } \\
\text { Aprendem. }\end{array}$ & \\
\hline & "Fui estudar por conta própria" & Fui. & \\
\hline
\end{tabular}

Fonte: Elaborado pelas autoras, Fortaleza, 2020.

Desta forma, depreende-se de nossa análise os ethé de submissão e de agência/empoderamento como os mais recorrentes. Tal variação decorre do contexto de fala e do referente a quem as mulheres se remetem, quando, por exemplo, vão falar de outras mulheres, assumem uma postura ativa, positiva e empoderada, contudo, quando vão relatar fatos acontecidos com elas mesmas, retornam ao posto de fragilidade e submissão.

Percebemos que a fragilidade a que nos referimos como característica desse ethos, ocorre quando essas mulheres se veem individualmente. Diante do coletivo, com um sentimento de pertença a um grupo, esses sujeitos femininos se empoderam e assumem novas características que denotam uma nova forma de agir, e representar-se. Dessa forma, 
reafirmamos nossa percepção inicial, de que houve o estabelecimento de um novo ethos, agora bem mais forte, empoderado, sugerindo características de feminilitude, que foge a concepção de docilidade, submissão, presentes no conceito de feminilidade, ao passo que criam suas próprias identidades e se posicionam reproduzindo características de fortaleza, perseverança, determinação.

As características de fragilidade e submissão se mostram transparentes no uso de recursos linguísticos como a voz passiva, na fala de uma das mulheres entrevistadas, "ele não me deixou dançar com ninguém”. Podemos ver por seu discurso que essa mulher obedece a seu parceiro como se esse fosse seu dono ou ocupasse uma posição de superioridade em relação a ela. Um outro recurso linguístico que demonstra a superioridade do homem sobre a mulher e sua passividade e aceitação da situação é o uso de verbos que demonstram semanticamente a autoridade desse homem, "Um dia determinou que eu ia passar a noite em pé". Como podemos ver o verbo "determinar" é usado em contextos onde existe uma relação de poder entre os falantes. O verbo por si só já nos traz essa conotação.

Para contrastar a ideia de submissão e fragilidade, as mulheres entrevistadas se utilizam de outros recursos linguísticos. Como no exemplo: "Nunca deixe de acreditar em si mesma. O seu crivo é o mais importante. Se você acredita em si e sabe de onde veio e onde vai chegar, não importa o caminho." O uso do verbo "acreditar" remete a ideia de empoderamento e esperança. A oração acima por completa nos remete a ideia de mulheres unidas como um grupo sócia forte, mulheres que incentivam outras mulheres, para que não passem por situações vexatórias, ou que se sintam inferiores e submissas a seus companheiros.

\section{Considerações finais}

Nossa análise buscou demonstrar a noção de ethos discursivo problematizada na Análise do Discurso Crítica (ADC) postulada por Norman Fairclough (2001 [1992]), e as noções de feminilidade e feminilitude explanadas por Martins Ferreira (2002) presentes no discurso de mulheres participantes da pesquisa. Buscamos demonstrar o modo como as mulheres entrevistadas se representam e representam o outro e como a relação gênero-raça-classe perpassa todo o seu discurso. O outro, muitas vezes o agressor, que lhes causou dor e sofrimento. Ou mesmo um outro, que apesar de não ter usado de força física, propriamente dita, também segregou, separou, e agrediu com seu discurso. 
Podemos concluir que os recursos linguísticos foram importantíssimos na análise dos discursos dessas mulheres, e que através de suas falas fica claro quais relações de poder e submissão estão inseridas, muitas vezes até mesmo sem ter essa percepção, e assim aceitá-las de forma passiva achando-as completamente naturais.

\section{Agradecimentos}

Agradecemos a Coordenação de Aperfeiçoamento de Pessoal de Nível Superior - CAPES e a Fundação Cearense de Apoio ao Desenvolvimento Científico e Tecnológico - FUNCAP pela concessão de bolsas de estudo de mestrado e doutorado que viabilizaram esta e outras pesquisas e ao Professor Dr. Lucineudo Machado Irineu pela condução da disciplina de Análise de Discurso Crítica no primeiro semestre de 2019 dentro do Programa de PósGraduação em Linguística Aplicada - PosLA UECE, na qual construímos grande parte deste trabalho sob sua supervisão e orientação.

\section{Referências}

CHARAUDEAU, P. Discurso político. São Paulo: Contexto, 2008.

DISCINI, N. Ethos e estilo. In: MOTTA, A. R.; SALGADO, L. Ethos discursivo. São Paulo: Contexto, 2011. p. 34-53.

FAIRCLOUGH, N. Análise textual: a construção das relações sociais do "eu". In: Discurso e mudança social. Coord. tradução: Izabel Magalhães. Brasília: UnB, 2001. p. 175210.

FAIRCLOUGH, N. Analysing discourse: textual analysis for social research. London: Routledge, 2003.

MARTINS FERREIRA, D. M. M. Discurso feminino e identidade social. São Paulo: Annablume/Fapesp, 2002.

MARTINS FERREIRA, D. M. M. Feminilidade e "feminilitude": identidades femininas. Intercâmbio. Revista do Programa de Estudos Pós-Graduados em Linguística Aplicada e Estudos da Linguagem. São Paulo, v. 21, p. 1-16, dez. 2010. Disponível em: <https://revistas.pucsp.br/intercambio/article/view/4447/3025>. Acesso em: 31 mar. 2020.

GALINKIN, A. L.; ISMAEL, E. Gênero. In: TORRES, Ana Raquel Rosas, et al. (orgs). Psicologia Social: Temas e Teorias. Brasília: Technopolitik, 2011. p. 503 - 557.

GARCIA, C. C. Breve história do feminismo. São Paulo: Claridade, 2011. 
GONÇALVES, J. B. C. Poder e afeto nas narrativas bíblicas: uma análise da construção do ethos discursivo nas parábolas contadas por Jesus. 2006. 350 f. Tese (Doutorado em Linguística) - Programa de Pós-Graduação em Linguística, Universidade Federal do Ceará, Fortaleza, 2006. Disponível em: http://www.repositorio.ufc.br/handle/riufc/35059. Acesso em: 31 mar. 2020.

IRINEU, L. M. Latinidade e imagens de si na tradição editorialística do Jornal do Brasil e do Clarín nos séculos XX e XXI: vestígios de mudança e traços de permanência. 2014. 336 f. Tese (Doutorado em Linguística) - Universidade Federal do Ceará, Centro de Humanidades, Departamento de Letras Vernáculas, Programa de Pós-Graduação em Linguística, Fortaleza, 2014. Disponível em: http://www.repositorio.ufc.br/handle/riufc/8922. Acesso em: 31 mar. 2020.

MAGALHÃES, I. Análise de Discurso Crítica: um método de pesquisa quantitativa. Brasília: Editora Universidade de Brasília, 2017.

MAINGUENEAU, D. A propósito do ethos. In: MOTTA, A. R.; SALGADO, L. Ethos discursivo. São Paulo: Contexto, 2011, p. 11-29.

RESENDE, V. de M.; RAMALHO, V. Análise de Discurso Crítica. São Paulo: Contexto, 2006.

SAFFIOTI, H. I. B. O poder do macho. São Paulo: Moderna, 1987.

Recebido em 31 de março de 2020

Aceito em 28 de abril de 2020 